\title{
The strength of ethnic ties: Routes into the labour market in spaces of segregation
}

\author{
Martin Klinthäll and Susanne Urban
}

\section{Linköping University Post Print}

\section{Tweet}

N.B.: When citing this work, cite the original article.

Original Publication:

Martin Klinthäll and Susanne Urban, The strength of ethnic ties: Routes into the labour market in spaces of segregation, 2014, Urban Studies.

http://dx.doi.org/10.1177/0042098014560498

Copyright: SAGE Publications (UK and US)

http://www.uk.sagepub.com/home.nav

Postprint available at: Linköping University Electronic Press

http://urn.kb.se/resolve?urn=urn:nbn:se:liu:diva-112710 
The Strength of Ethnic Ties:

Routes into the labour market in spaces of segregation.

\begin{abstract}
This study analyses whether ethnic segregation leads to social isolation and lack of access to valuable informal channels into the labour market. We use a survey of Swedish-born young adults in Stockholm, whose parents were born either in Turkey (Stratum T) or in Sweden (Stratum S). Stratum $T$ was randomly sampled, whereas Stratum $S$ was sampled according to the residential distribution of Stratum T. Our results show that persons in Stratum T use informal contacts more often in order to find employment than Stratum S. Living in immigrant-dense areas increases the likelihood of finding employment through informal contacts. For Stratum T, co-ethnic contacts are more important than other contacts, in particular if they are neighbours. Access to ethnic networks and the use of ethnic contacts in the labour market differ between persons of Turkish, Kurdish and Assyrian/Syriac backgrounds. In contrast to the isolation thesis, this study shows that young adults in immigrantdense neighbourhoods have access to and benefit more from informal channels in order to find ways into labour market.
\end{abstract}

\title{
Introduction and aim of the study
}

Opportunities in the labour market are shaped not only by the individual's personal characteristics, but also by the economic, spatial and social context in which the individual is embedded. In this paper we explore whether ethnic segregation is associated with social isolation and limited access to informal channels to the labour market.

Residential segregation has been presented as a threat toward the social cohesion of cities, and segregated neighbourhoods as pockets of poverty leading to social exclusion (Andersson et al 2010). Ethnic segregation, in particular, is discussed in terms of isolation and lack of links to the majority population thereby hampering access to the labour market for immigrants and their children. In this paper we present analyses of access and mobilisation of different kinds of informal channels for young individuals born in Sweden with parents born in Turkey, in neighbourhoods with different levels of ethnic concentration. Our results indicate that ethnic residential segregation is not associated with social isolation, since it includes access to ethnic networks that provide important channels into the labour market. While ethnic segregation in the labour market may contribute to socioeconomic segregation along ethnic lines, our results indicate that access to ethnic ties should be considered an important resource in the labour market. 
The study uses data from a survey that delineate access to social contacts and what kind of social contacts that lead to employment. First we explore the networks to which respondents have access. Second we investigate the extent to which individuals find jobs through informal channels, and whether this is associated with ethnic concentration in the neighbourhood of residence. We also look at the relative importance of weak and strong ties, as well as ethnic and local contacts. We study young adults born in Sweden with parents born in Turkey ("Stratum T"). A corresponding sample of young Swedish-born adults with parents born in Sweden ("Stratum S") is used as reference group. Stratum S is sampled to have the same geographical distribution in terms of neighbourhoods as Stratum T. Hence, the purpose of this article is to explore the isolation thesis in terms of access to informal channels and importance of different kinds of ties for job finding among young adults in Stratum T compared with Stratum S, who were born in the same country and live in a similar socio-geographic context.

\section{Previous research and theoretical framework}

Residential segregation and negative "neighbourhood effects", lack of access to relevant social networks and social capital, have been raised as important hampering factors for establishment in the labour market. In particular ethnic housing segregation is discussed as a hindrance for integration of ethnic minorities in the labour market, foremost from lack of social contacts leading out of the local community, but also from lack of role models and development of local disintegrative cultures (van der Laan Bouma-Doff 2007). The isolation thesis has not been unquestioned. In this section we give a short overview of the main ideas behind the isolation thesis and the critique.

The isolation thesis may be traced back to a discussion inspired by Wilson (1997) on negative outcomes of living in a socially deprived area. Different kinds of social interactions, such as collective socialisation, impact of role models, collective efficacy, social control, and relative deprivation, are important aspects in the proposed neighbourhood-effect literature. One part of these arguments is specifically focused on negative effects of ethnic clustering; a low level of interaction with the majority population will lead to difficulties of learning the majority language, lack of country specific knowledge and lack of valuable social capital. Furthermore, a concentration of groups that encounter discrimination will lead to enhanced feelings of exclusion, reduce expectations of obtaining employment and thereby lower the motivation to apply for jobs. More or less advanced statistical methods are developed in order to isolate the endogenous effects (effects from living in the area), from exogenous effects (external factors 
that affect residents in the area similarly), and sorting effects (correlated effects due different sorting mechanisms in the housing market).

Since most of these analyses are based on register data, the actual social relations are not observed but just assumed. The difficulty of isolating endogenous effects from correlated and exogenous (Manski 2000) is a repeated theme in the neighbourhood-effect literature. One important part of the problem is how to isolate effects that stem from contacts with neighbours when social relations in the neighbourhood are not known. Most studies on neighbourhood-effects in Sweden show that the neighbourhood has a minor impact on labour market careers when taking account of individual and family characteristics (Brännström and Rojas 2012).

A number of researchers (eg. van Kempen and Özükren 1999, Musterd 2005, Magnusson and Özükren 2010, Brännström and Rojas 2012) put the neighbourhood-effect and thereby the isolation thesis into question, apart from the statistical problem of measuring neighbourhoodeffect - do ethnic residential concentration really hamper social inclusion of ethnic minorities? While Wilson writes about concentration of minority populations in poor areas, researchers in Sweden write about foreign-born, or immigrants. Urban (2009) shows that the socioeconomic situation in the neighbourhood, rather than immigrant density, explains differences in economic outcomes from growing up in immigrant-dense areas. Drever and Hoffmeister (2008) argue that the debate about whether immigrants gain more by investing in networks made up of their co-ethnics than in bridging networks linked to the wider society is in fact a debate about the value of the social capital in each of these network configurations. Borjas (e.g. 1992) proposes that, depending on the situation in the ethnic group as a whole, there may be positive as well as negative "ethnic" capital effects. Research on the importance of ethnic networks (e.g. Portes 1995), ethnic economy and ethnic enclaves (Waldinger 1996, Zhou 2004) emphasizes the advantages that may result from resourceful ethnic networks and ethnic concentration. Other important arguments against the isolation thesis is for example that ethnic segregation in European cities is not as pronounced as in the US and that social life is not as dependent of neighbourhood (van der Laan Bouma-Doff 2007, van Eijk 2010, Pinkster 2009, Edling and Rydgren 2012).

While the starting point for Wilson in fact was inequalities following from obstacles faced by minorities in the labour market, the structural context seems to have been lost in much of the 
efforts to measure the neighbourhood-effect. It is also argued that it is not the neighbourhood per se that is of importance, but rather the socioeconomic processes that drives segregation and polarization that is manifested both as housing segregation and in the labour market (Scarpa 2014). The value or usefulness of an individual's network is determined by contextual factors such as situations in the labour market, regulations, political and socio-cultural processes, and individuals will mobilise networks differently depending on the value that is embedded in the network. The use of informal channels may in this way be viewed not only as a determinant of the individual's or group's position in the labour market, but also an outcome. Hence, studies of urban inequality and segregation demand a contextual perspective where individual and structural explanatory factors meet, since reproductions of inequality and segregation are complicated processes that involve individual resources, social networks as well as structural preconditions.

The concepts of formal/informal channels and weak/strong ties are important in the network studies literature and useful for analysing how social contacts are used. Rees (1966) importantly pointed out the difference in using formal sources of information and informal sources in the job-search process. Research on the importance of different kinds of social contacts, networks and social capital in job search strategies have since then been flourishing both in economic and sociological literature. According to a literature review by Ioannes and Datcher Loury (2004), there are conflicting results from studies on differences in the use of informal contacts by age, race and ethnicity. Some researchers find small differences across ethnic groups regarding job search strategies, and others find differences in the outcome of different job search strategies. Drever and Hoffmeister (2008), for example, use data from the German Socio-Economic Panel and conclude that nearly half of all foreign born job changers found their positions through networks and that the most vulnerable to unemployment - the young and the less educated - were especially likely to rely on them. Ioannes and Datcher Loury present research that shows that informal job-search strategies are more common in high-poverty neighbourhoods than in low-poverty neighbourhoods. Research on the extent to which foreign born and natives use informal ways into the labour market in Sweden shows mixed results. Olli Segendorf (2005) finds that non-European immigrants more often use informal contacts, such as friends and acquaintances, compared with natives, in their general search strategies. Behtoui (2008), who uses data on how employed persons obtained their current job, finds that formal strategies are more important. 
A number of studies, inspired by Granovetter's (1973) concept of "weak and strong ties", have emphasised the importance of an approach that systematically investigates social network ties (Granovetter 1995, Lin 2001; De Graaf et al. 1988, Flap and Boxman 2001). A number of researchers have argued that bridging social capital, in terms of access to contacts with natives, is especially important for ethnic minorities in presence of discrimination (for an overview see Lancee 2010, Mouw 2002). A number of studies do not find any negative association between ethnic concentration and contacts between ethnic minority and majority population (Drever 2004, Fong and Isajiw 2000, Sigelman et al 1996), but further support to the isolation thesis is given by a number of studies that shows a negative relationship between ethnic residential concentration and social contacts with the majority population. For example, van der Laan Bouma-Doff (2007) concludes that ethnic concentration is strongly negatively associated with the probability of maintaining contacts with native Dutch. Ethnic bridges (informal ties between ethnic minorities and native Dutch) are less frequent in areas with high ethnic concentrations. This is however only significant for non-deprived ethnic minorities. Vervoort (2012) also concludes that ethnic residential concentration is associated with less social ties between ethnic minorities and native Dutch, and in addition, that ethnic residential concentration constrain the strength of the bridging contacts in terms of support and advice.

Studies of what contacts are actually being used - "activated social capital" - have been critiqued for underestimating the effect of social capital (Lancee 2010). Lin and others (Lin 2001) argue that the social network has an impact on social status which, in turn, has an impact on possibilities on the labour market. The actual person that provided information about the job opportunity is, in this view, not as important as the cultural value of the social capital that is accessible through the social network. This critique points to an important distinction of having access to a network, and of mobilising the network (Lin 1999). Access to relevant networks and contacts that might lead to employment (through referrals or unofficial information on job openings) requires that networks are linked to the labour market. Hence, foreign born individuals and their children that are included in ethnic networks with weak attachment to the labour market risk having low access to relevant networks. However, this argument only holds if individuals do not use contacts outside the ethnic network. 


\section{Labour market context, migration history, ethnic communities}

In order to control for differences regarding labour market opportunities on the demand side, we limit the study to Stockholm. By limiting the study spatially, we isolate a post-industrial urban context where individuals in our targeted population face similar opportunity structures. Stockholm is also interesting because studies have reported evidence on a growing economic and ethnic residential segregation in the Stockholm region (e.g. Hårsman 2006); immigrants more often live in neighbourhoods with low mean incomes, but historically not clustered by ethnic origin.

Regarding labour market opportunities from a supply side perspective, we limit the study population to young adults who were born in Sweden. This means that the individuals in the study have gone through the same educational system and that systematic differences cannot be attributed to factors such as international transferability of skills, signalling devices, or language. The study deals with ethnic residential segregation and the isolation hypothesis. Therefore, the main reason to target young adults whose parents were born in Turkey is that immigrants from Turkey score highest on segregation indices (Hårsman 2006), and display relatively high concentrations in a few areas located in suburbs in Botkyrka and Södertälje municipalities south of Stockholm city (Magnusson and Özukren 1997).

Migration from Turkey in different waves often came to Sweden through chain-migration (Alpay 1980, Björklund 1981, see also Svanberg 2005). The individuals in the targeted sample of our survey were born in Sweden between 1982 and 1985, but the time span for immigration to Sweden by their parents is wide and includes the most important large waves of immigration from Turkey; Turkish labour migrants in the 1960s and early 1970s, Assyrian/Syriac refugee immigration in the mid to late 1970s and to a lesser extent Kurdish refugee immigration, primarily from 1980. Immigration from Turkey due to family reunification and family formation has also been large during the whole period.

A number of studies have shown that the ethnic communities in these groups are vibrant in Sweden (e.g. Berg 1994; Pripp 2001; Khayati 2008). However, the participation in ethnic community associations seems to be weaker in the generation born in Sweden (Akis and Kalaylioglu 2012), although a low level of activity in formal associations does not rule out a high level of activity in informal friendship networks within the ethnic group (Behtoui 2012). 


\section{Survey}

The survey data was collected by Statistics Sweden during the period October 2011 to March 2012. The population consists of persons in ages 26-29, residing in the labour market region of Stockholm-Solna (excluding Uppsala) and born in Sweden with both parents born either in Sweden (Stratum S) or in Turkey (Stratum T). The residence pattern of 26-29 year old persons with parents born in Turkey differs significantly from the overall residence pattern in the region. Segregation indices show that 61 per cent would have to move to another neighbourhood in order to get the same distribution over neighbourhoods compared to the total population whereas the corresponding number for those in the same age group born in Sweden is 28 per cent. In order to keep constant the neighbourhood context, the survey sample was drawn to give Stratum $S$ the same geographical distribution as Stratum T. Neighbourhoods are defined by SAMS (small area codes, an often used measure of neighbourhoods in Sweden). The sample consists of a total of 1800 individuals (close to the total population of Stratum T), of which 770 (43 per cent) responded to the questionnaire. The response rate is 56 per cent, taking account of the estimated over-coverage.

Employment is the most common labour market status. Stratum T displays a higher share of employed individuals than Stratum S (74 percent compared to 67), whereas Stratum S displays a higher share enrolled in education compared with Stratum T. The distribution of employed versus unemployed is similar in the two strata when students are omitted. Information on ethnic backgrounds was collected through questions to respondents in Stratum $\mathrm{T}$ about ethnicity and language knowledge. This was done with the aim to be able to identify access to ethnic contacts; the ethnic identity as such is not our focus here. We have chosen to term these categories "ethnic backgrounds". As these questions were asked only to Stratum T, all respondents in Stratum $\mathrm{S}$ were assigned Swedish background. The most common ethnic background in Stratum T was Turkish (50\%), followed by Assyrian/Syriac (35\%) and Kurdish (11\%). This reflects the migration history from Turkey to Sweden, with large-scale Kurdish immigration being primarily a feature of the 1980s. Those born in Sweden 1982-85 with Kurdish parents born in Turkey are therefore relatively few.

We connected register information on the share of the population born in Turkey in the neighbourhood of residence of the respondents, as well as median income in the neighbourhood. The two variables display a significant negative correlation (Pearson's $\mathrm{r}=$ - 
0.57, p 0,000). Neighbourhoods are classified into three groups according to the share of immigrants from Turkey living in the area, and used as a proxy for access to local co-ethnic contacts. Most of the respondents live in areas with few inhabitants born in Turkey (mean proportion is 3.8 per cent). A small number of neighbourhoods display more than 10 per cent of the residents born in Turkey, and we classified these areas as having a high concentration born in Turkey. The middle category displays 5-10 per cent born in Turkey, and a low concentration less than five per cent. The information on the share of the population born in Turkey was retrieved from register data and therefore not possible to separate into ethnic categories. The different ethnic backgrounds are not equally distributed; those with Assyrian/Syriac ethnic background more often live in areas with medium-high concentration born in Turkey. Since we had lower response rates for Stratum S in the areas with a high share of the population born in Turkey, Stratum $\mathrm{T}$ is somewhat over-represented in those areas.

\section{Access to ethnic networks and the importance of distance}

Strength and importance of different social contacts and access to ethnic ties are measured in several ways in the survey. First we ask about the characteristics of their three closest friends, second we ask about membership and activity in different kinds of organisations, and third we ask questions about the person (if any) that was most important for applying to (if currently unemployed) or landing (if employed) the job. For this study we do not elaborate on the density, internal organization or access to resources, etc., within separate networks but focus only on the social ties that the individual have access to. Selected characteristics of the three closest friends are shown in Table 1.

\section{Table 1 about here}

Having close friends with foreign backgrounds is much more common in Stratum T; those with Assyrian/Syriac ethnic background display the highest proportion friends with foreign backgrounds. Those with Kurdish ethnic background are more often friends with persons of the same ethnic background compared with those of other ethnic backgrounds in Stratum T, and those of Turkish ethnic background display the lowest proportion of friends of the same ethnic background. The friends of Stratum $\mathrm{T}$ more often live in the same neighbourhood compared to friends of Stratum S, in particular among those of Kurdish ethnic background, whereas those of Swedish ethnic background more often had friends in other places in Sweden. Hence, the results indicate that those with parents born in Turkey more often socialise within the neighbourhood compared to those of Swedish background. 
Regarding formal associations, respondents with Assyrian/Syriac ethnic background have the highest proportion reporting activity in associations (participating in activities at least once a year), with 50 per cent active. Those with Swedish background are a little less active (40 per cent), and the activity is the lowest among those with Turkish and Kurdish ethnic backgrounds (34 and 21 per cent respectively). Respondents with Assyrian/Syriac ethnic background are also the most active in associations based on ethnic belonging (self-defined by respondent) compared to those of other backgrounds.

Hence, many young adults in Stratum $\mathrm{T}$ seem to have access to social contacts with the same ethnicity both as close friends and in formal associations. Our data indicate that communities that were formed by their parental generation are also accessible to, and accessed by, the second generation, if not in an organized form like in some Assyrian/Syriac groups, then through informal friendship. The social ties of Stratum $\mathrm{T}$ are geographically closer than those of Stratum S. The data show that the ethnic groups within Stratum T have less contact with the native population in comparison with Stratum $S$ in terms of close friends. The close friends of Stratum $\mathrm{S}$ are also ethnically homogeneous since they do not have many foreign born contacts even though they live in the same areas.

\section{Channels that led to a job}

In this section we explore whether residence in areas with high concentrations of persons born in Turkey implies that employment is less often landed through informal channels, as the isolation thesis propose. We use information from the survey on how our respondents found information about their current or latest job. There were in total 758 persons in the survey that currently or previously had a job, i.e. were employed or self-employed. Respondents that found their job through a personal contact were asked a number of questions about the person that was most important for finding the job. The most common way of finding information about the job is through hints from friends and relatives or through direct contact with the employer, in Stratum $\mathrm{T}$ as well as in Stratum $\mathrm{S}$ (table 2). Stratum $\mathrm{T}$ uses these sources of information to a larger extent compared with Stratum S, whereas Stratum S uses formal contacts such as the Public Employment Agency to a larger extent. Finding information through a private employment agency and finding the job through a temporary employment agency is also more common in Stratum S. According to these results, informal channels of information are more common in Stratum T compared with Stratum S, who more often rely on formal institutional services. Stratum T seem to benefit from resources accessible through 
their social contacts, possibly because they were less successful in finding jobs through formal channels, which leaves informal channels as an alternative.

Table 2 about here

Table 3 about here

All respondents were asked whether there was a particular person that was important for them when they found their current job, started their current firm, or found the most recent job they had. Among employed, self-employed and unemployed/students with work experience, a total of 226 persons defined their relationship with this person in a follow-up question (excluding those who defined the person as employed in an employment agency or "other"). Multiple responses were possible. The results (table 3) show that Stratum T more often use strong ties; partners, relatives and friends, whereas Stratum $\mathrm{S}$ use weak ties such as acquaintances and colleagues to a larger extent.

The survey results also show that the person reported to be particularly important is more often self-employed regarding Stratum T (29 per cent) compared with Stratum S (14 per cent), and Stratum $\mathrm{T}$ also use neighbours to a larger extent (39 per cent) compared with Stratum $\mathrm{S}$ (27 per cent).

Table 4 about here

Regarding ethnic and local contacts, table 4 shows that as much as 61 per cent in Stratum T who found the job through a particular person reported that this person was of the same ethnic background as the respondent. A large part of the persons that were considered to be important in order to acquire the job were both neighbours and co-ethnics; 80 per cent of the important persons who were neighbours were also co-ethnic, and half of the important persons outside the neighbourhood were co-ethnic contacts. Hence, contacts in the neighbourhood seem to be particularly important if they are co-ethnic, but co-ethnic contacts outside the neighbourhood are as important as local co-ethnic contacts. Contrary to the isolation hypothesis, co-ethnic contacts in the neighbourhood seem to be an important channel into the labour market, but ethnic contacts outside the neighbourhood seem to be equally important.

Next, we estimate logit regressions in order to compare the importance of different channels of job information when taking account of educational level and type of neighbourhood. The variance that was explained by neighbourhood level (in an "empty model") was not significant, why we chose not to use multilevel models. 
The first model (table 5) combines responses from the question on information that was important for applying for the job and the questions about a specific person that was important in order to acquire the job. We have created a dichotomous variable for using an informal or formal channel of information about the current or latest job. An informal channel is used when information about the job was given by informal contact with the employer, hint from relatives, or the person most important for finding the job was a spouse, parent, relative, friend, acquaintance, or a colleague. A formal channel is used when information about the job was found through an ad in newspaper or workplace homepage, the public employment agency, a private employment agency, a staffing company, or when the person most important for finding the job was person at an employment agency or an employer who is not an informal contact. 170 of the respondents did not answer any of the questions designed to capture formal and informal channels into the labour market. 71 persons reported both informal and channels. Informal channels were given priority in the coding.

Table 5 about here

An odds ratio above unity means that the probability of using an informal channel is higher compared to the reference category, and table 5 shows that those of Turkish ethnic background more often obtain job information through informal channels compared to Stratum S. Those of Assyrian/Syriac ethnic backgrounds also tend to use informal channels more often than Stratum S, but this result is not statistically significant on the five percent level. Less educated respondents use informal channels more often whereas higher educated use formal channels. Type of neighbourhood has an effect; the use of informal channels is higher in areas with higher proportions born in Turkey. Taking account of neighbourhood reduces the odds ratios for 'Assyrian/Syriac', meaning that those of Assyrian/Syriac ethnic backgrounds who use informal channels are over-represented in areas with many immigrants from Turkey.

Informal channels could be either weak or strong ties. In order to analyse the relative importance of weak and strong ties we constructed a variable with three values; strong tie, weak tie, or formal contact. A person counts as having used a strong tie to obtain the job if they answered that a spouse, parent, relative or friend was important to obtain the job. A weak tie was used if the important person was an acquaintance, employer or private investor, or that information came from acquaintances. If neither a weak nor a strong tie had been used to obtain the job, the respondent counts as having used a formal channel, as defined above.

Table 6 about here 
Table 6 shows the results from a multinomial regression on the relative odds of using a strong or a weak tie in relation to using formal channels. The reference is Stratum S, low education and resident in a neighbourhood with less than 5 per cent born in Turkey. Those with higher education display significantly less use of strong and weak ties, which is consistent with research showing that highly educated to a larger extent use formal contacts. Informal channels are used more often among those of Turkish ethnic background, but there is no significant difference between using strong or weak ties. Those of Assyrian/Syriac ethnic backgrounds use weak ties significantly more often, something which seems be associated with relatively high self-employment rates in this group. Those who live in areas with higher concentrations of inhabitants born in Turkey more often use informal ties, and especially strong ties.

In addition, we estimated the odds of finding the job through direct contact with the employer and found that Assyrian and Syriac respondents to a higher degree find jobs through direct contact with employers. We also estimated the odds of finding the job through a co-ethnic contact and found that Assyrians and Syriacs to a much larger extent use co-ethnic contacts, compared with those of Turkish or Kurdish ethnic backgrounds. Hence, access to a wide ethnic network containing weak ties to many self-employed persons seems to be important for those of Assyrian/Syriac ethnic backgrounds when finding employment. The models were also tested with gender as a variable; this resulted in minor changes in the odds ratios and reduced significance levels. Males use formal channels more often than females do, but separate regressions per gender shows that this is similar across ethnic backgrounds.

\section{Summary and discussion of results}

This paper investigates whether ethnic residential segregation hamper access to the labour market for young persons born in Sweden with parents born in Turkey, trough isolation in areas with higher access to co-ethnics and less access to natives. The results of this survey directed to young persons from the most segregated ethnic groups in Stockholm shows no support for the isolation thesis. Living in a neighbourhood with higher concentration of people born in Turkey does not reduce the usage of informal channels that lead to a job. Instead we found the opposite result.

The results show that those with parents born in Turkey (Stratum T) more often have social contacts that live in the same neighbourhood, compared with those who have parents born in 
Sweden (Stratum S). There are varying patterns across groups; those of Assyrian/Syriac ethnic background display more organised ethnic networks, whereas networks among those of Kurdish background include more close friends of the same ethnicity. The networks also contain bridges, not all friends have the same ethnicity and persons that are important in order to find jobs are not always of the same ethnicity.

From the survey we can conclude that Stratum $\mathrm{T}$ to a larger extent use informal channels for information on the jobs that they actually obtain, compared with Stratum S. Stratum T also use strong ties, neighbours and self-employed persons more often than Stratum S. Logit estimations show that there are large differences between Stratum S and Stratum T, but also heterogeneity across ethnic groups within Stratum T. Those of Turkish and Assyrian/Syriac ethnic background more often use informal channels and less often formal channels of information to find jobs. Those of Assyrian/Syriac ethnic background more often obtained their job through direct contact with employers, through weak ties and through ethnic ties. These differences remain significant also when controlling for level of education. Respondents with higher education more often use formal channels of information, and weak ties more often than strong ties, while respondents with lower education use co-ethnic contacts more often. Living in residential areas with higher concentrations of inhabitants born in Turkey is associated with a higher probability of using informal channels, and in particular strong ties. Since we also can show that a neighbour is of more importance when he or she has the same ethnicity, we argue that ethnic networks are important and interdependent of the effect of living in an area with higher proportions of residents born in Turkey. Our results are in line with previous research made internationally and in Sweden (Olli Segendorf 2005) on general search strategies. Behtoui (2008) finds that, for foreign born in Sweden, formal channels are more important for finding employment. Hence, whereas foreign born had to depend on formal channels into the labour market, it seems from our study that their children have more use of informal channels accessible through ethnic networks that were established by their parents. Our study also shows that the results are sensitive to the level of aggregation of groups that are included in the analyses. There is a great risk that results from analyses of large accumulations of heterogeneous immigrant categories, such as "non-European" or "African" or even "born in Turkey" lead to generalised conclusions that are not valid for specific sub-groups or categories. The migration history and contextual preconditions of each group needs to be considered in the analyses of accessibility, mobilisation and resources of social contacts. 
In contrast to the isolation thesis this study shows that young adults in immigrant-dense neighbourhoods find ways into employment through the strength of ethnic ties. Co-ethnic social contacts and formalised ethnic networks are created in a historic process alongside of chain migration, settlement, development of associations, and clusters in the labour market that are developed in parallel with ethnic housing segregation. The notion that housing segregation causes social isolation is therefore misleading. Instead, we should acknowledge that resources embedded in ethnic networks, local and not local, are important in counteractive strategies used in response to barriers in the labour market. The use of informal channels to employment is more common in more immigrant-dense areas, which clearly speaks against the social isolation thesis. The ethnic networks hold potential means of breaking out of negative aspects from segregation instead of enhancing social isolation. We argue therefore that the main cause of the strong correlation between ethnic segregation and socioeconomic segregation lies in the labour market. However, if co-ethnic ties become a major channel into the labour market (for natives as well for foreign born), the risk is that there will be increased ethnic division of the labour market, including unequal terms for different ethnic groups, which in turn will reinforce socioeconomic segregation along ethnic lines. The policy implication is that segregation in the labour market, and not ethnic housing segregation, should be a main concern for urban development policy.

\section{References}

Akis, Y. and Kalaylioglu M. (2012) Turkish Associations in Metropolitan Stockholm: Organizational Differentiation and Socio-Political Participation of Turkish Immigrants. Stockholm University: Stockholm.

Alpay, Ş. (1980) Turkar i Stockholm. En studie av invandrare politik och samhälle. Liber: Stockholm.

Andersson, R., Bråmå, Å., Holmqvist, E. (2010) Counteracting Segregation: Swedish Policies and Experiences. Housing Studies 25(2), pp. 237-256.

Behtoui, A. (2008) Informal Recruitment Methods and Disadvantages of Immigrants in the Swedish Labour Market, Journal of Ethnic \& Migration Studies 34(3), pp. 411-30.

Behtoui, A. (2012) Incorporation of children of immigrants: the case of descendants of immigrants from Turkey in Sweden, Ethnic and Racial Studies DOI: 10.1080/01419870.2012.696667

Berg, M. (1994) Seldas andra bröllop. Göteborg: Göteborgs universitet. 
Björklund, U. (1981) North to Another Country. The Formation of a Suryoyo Community in Sweden. Stockholm: Stockholms Universitet.

Borjas, G. (1992) Ethnic Capital and Intergenerational Mobility, The Quarterly Journal of Economics 107(428), pp.124-150.

Brännström, L. and Y. Rojas (2012) Rethinking the Long-Term Consequences of Growing Up in a Disadvantaged Neighbourhood: Lessons from Sweden, Housing Studies, 27(6), pp. 729747.

De Graaf, P. Dirk, N. and Flap, H. (1988) 'With a Little Help from My Friends': Social Resources as an Explanation of Occupational Status in West Germany, The Netherlands and the United States, Social Forces, 67(2), pp. 452-472.

Drever, A. (2004) Separate Spaces, Separate Outcomes? Neighbourhood Impacts on Minorities in Germany, Urban Studies, 41(8), pp. 1423-1439.

Drever, A. I., and Hoffmeister, O. (2008) Immigrants and Social Networks in a Job-Scarce Environment: The Case of Germany, International Migration Review 42(2), pp. 425-448.

Edling, C. and J. Rydgren (2012) Neighborhood and Friendship. Composition in Adolescence. SAGE Open October-December 2012, pp. 1-10. DOI: $10.1177 / 2158244012466249$

Flap, H. and Boxman, E. (2001) Getting started: The influence of social capital on the start of the occupational career. In: Lin, N., Cook, K. and Burt, R. (Eds.) Social Capital: Theory and Research, pp. 159-184. New York: Aldine de Gruyter.

Fong, E. And Isajiw, W. W (2000) Determinants of friendship choices in multiethnic society, Sociological Forum 15(2), pp. 249-271.

Granovetter, M. (1973) The Strength of Weak Ties, American Journal of Sociology 78(6), pp. $1360-1380$.

Granovetter, M. (1995) Getting a job: a study of contacts and careers. Chicago: University of Chicago Press.

Hårsman, B. (2006) Ethnic Diversity and Spatial Segregation in the Stockholm Region. Urban Studies 43(8), pp. 1341- 1364.

Ioannes Y. M. and Datcher Loury, L. (2004). Job information Networks, Neigborhood Effects and Inequality. Journal of Economic Literature. Vol XLII (December 2004), pp. 1056-1093. Khayati, K. (2008) From Victim Diaspora to Transborder Citizenship?: Diaspora formation and transnational relations among Kurds in France and Sweden. Linköping University: Linköping. 
Kramarz, F. and O. Nordström Skans (2011) When strong ties are strong - networks and youth labor market entry. Working paper 2011:18, Uppsala: IFAU.

Lancee, B. (2010) The economic returns of immigrants boonding and bridging social capital: the case of Netherlands, International Migration Review 44(1), pp. 202-226.

Lin, N. (1999) Social Networks and Status Attainment. Annual Review of Sociology 25, pp. 467-87.

Lin, N. (2001) Social Capital. A Theory of Social Structure and Action. Cambridge: Cambridge University Press.

Magnusson, L. and Özükren S. (2010) The housing careers of Turkish Households in Middlesized Swedish Municipalities, Housing Studies 17(3), pp. 465-486.

Manski, C. (2000) Economic Analysis of Social Interactions, Journal of Economic Perspectives 14(3), pp. 115-136.

Mouw, T. (2002) Racial Differences in the Effects of Job Contacts: Conflicting Evidence from Cross-Sectional and Longitudinal Data, Social Science Research 31(4), pp. 511-538.

Musterd, S. (2005) Social and Ethnic Segregation in Europe; levels, causes and effects. Journal of Urban Affairs, 27(3), pp. 331-348.

Olli Segendorf, Å. (2005) Jobsearch by immigrants in Sweden, in: Å . Olli Segendorf (Ed.), Job Search Strategies and Wage Effects for Immigrants, pp. 1-48. Stockholm: Stockholm University.

Pinkster, F. (2009) Neighborhood-based Networks, Social Resources, and Labor Market Participation in Two Dutch Neigborhoods. Journal of Urban Affairs, 31(2), pp. 213-231

Portes, A. (1995) Children of Immigrants: Segmented Assimilation and its Determinants, in: A. Portes (Ed.) The economic sociology of immigration, pp. 248-280. New York: Russell Sage.

Pripp, O. (2001) Företagande i minoritet: om etnicitet, strategier och resurser bland assyrier och syrianer $i$ Södertälje. Tumba: Mångkulturellt centrum.

Rees, A. (1966) Information Networks in Labor Markets. American Economic Review, 56(1/2), pp. 559-566.

Scarpa, S. (2014) The impact of income inequality on economic residential segregation: The case of Malmö, 1991-2010. Urban Studies. Published online before print, pp. 1-17, April 7, 2014.

Sigelman, L., Bledsoe, T. Welch, S. And Combs, M. W. (1996) Making contact? Black-White social interaction in an urban setting, American Journal of Sociology 101(5), pp. 1306-1332 
Svanberg, I. (2005) Tusen år av invandring: en svensk kulturhistoria. Stockholm: Dialogos Förlag.

Urban, S. (2009) Is the Neighbourhood Effect an Economic or Immigrant Issue? A Study of the Importance of the Childhood Neighbourhood for Future Integration into the Labour Market, Urban Studies 46(3), pp. 583-603.

van Eijk, G. (2010) Unequal networks. Spatial segregation, relationships and inequality in the city. Delft: Delft University of Technology.

van Kempen, R. and Özükren, A. (1999) Ethnic Segregation in Cities: new forms and explanations in a dynamic world, Urban Studies 53(10), pp. 1631-1656.

van der Laan Bouma-Doff, W. (2007) Confined Contact: residential segregation and ethnic bridges in the Netherlands, Urban Studies 44:5(6), pp. 997-1017.

Vervoort, M. (2011) Ethnic Concentration in the Neighbourhood and Ethnic Minorities Social Integration: Weak and Strong Ties Examined, Urban Studies 49 (4), pp. 897-915.

Waldinger, R. (1996) Still the promised city? New Immigrants and African-Americans in Post-Industrial New York. Berkely, CA: Harvard University Press.

Wilson, J. W. (1997) When Work Disappears. The World of the New Urban Poor, New York: Vintage Books.

Zhou, M. (2004) Revisiting ethnic entrepreneurship: convergences, controversies, and conceptual advancements, International Migration Review 38(3), pp. 1040-74.

Table 1. Characteristics of three closest friends by ethnic background

\begin{tabular}{|c|c|c|c|c|c|}
\hline Friend $1+2+3$ & $\begin{array}{c}\text { Swedish } \\
n=858 \\
\%\end{array}$ & $\begin{array}{c}\text { Assyrian/ } \\
\text { Syriac } \\
n=397 \\
\%\end{array}$ & $\begin{array}{c}\text { Kurdish } \\
\mathrm{n}=131 \\
\%\end{array}$ & $\begin{array}{c}\text { Turkish } \\
\mathrm{n}=535 \\
\%\end{array}$ & $\begin{array}{c}\text { Other/ } \\
\text { Unknown } \\
n=42 \\
\%\end{array}$ \\
\hline \multicolumn{6}{|l|}{ Background/origin } \\
\hline Foreign background & 17.7 & 85.6 & 84.0 & 78.9 & 64.3 \\
\hline Same as respondent & 82.3 & 64.5 & 71.8 & 51.8 & 33.3 \\
\hline \multicolumn{6}{|l|}{ Residence of friend* } \\
\hline In the neighbourhood & 17.8 & 22.9 & 29.0 & 25.6 & 19.0 \\
\hline In Stockholm area & 55.9 & 57.2 & 57.3 & 64.3 & 54.8 \\
\hline In Sweden & 21.8 & 17.9 & 8.4 & 6.9 & 14.3 \\
\hline Abroad & 2.8 & 0.5 & 3.8 & 1.1 & 7.1 \\
\hline
\end{tabular}

The total regarding friends' place of residence does not add up to 100 per cent, because of internal non-response.

\section{Table 2. How did you find information about the job?}




\begin{tabular}{lll}
\hline $\mathrm{n}=605$ & Stratum S, \% & Stratum T, \% \\
\hline
\end{tabular}

Formal channels

Newspaper ad

$\begin{array}{rr}3.0 & 2.2 \\ 8.5 & 9.7 \\ 18.3 & 11.6 \\ 3.0 & 2.4 \\ 3.4 & 1.9 \\ 36.2 & 27.8\end{array}$

Employers webpage

Public Employment Agency

Private Employment agency

Temporary employment agency

27.8

Informal channels

Hints from friends and relatives

$23.4 \quad 28.4$

Contacted employer directly

$20.0 \quad 23.2$

Contacted by employer

$11.9-14.1$

Subtotal

Other channels

Total

100

100

Table 3. Relation to the person who were particularly important for obtaining the job (multiple responses possible).

\begin{tabular}{lrr}
\hline & Stratum S & \multicolumn{1}{l}{ Stratum T } \\
\hline & \multicolumn{1}{l}{ 92 individuals } & 134 individuals \\
& 104 marks & 146 marks \\
Strong tie & 13.5 & 11 \\
Spouse, partner etc & 15.4 & 34.9 \\
Relatives & 27.9 & 24.7 \\
Friend & 56.8 & 70.6 \\
Subtotal & & \\
& & \\
Weak tie & 16.3 & 12.3 \\
Acquaintance & 17.3 & 6.8 \\
Colleague & 9.6 & 10.3 \\
Employer & 43.2 & 29.4 \\
Subtotal & & \\
& 100 & \\
Total & & \\
\hline
\end{tabular}

Table 4. Cross tabulation of neighbour as important person by co-ethnicity of important person (only Stratum T).

\begin{tabular}{lcccccc}
\hline & \multicolumn{2}{c}{ Neighbour } & \multicolumn{2}{c}{ Not neighbour } & \multicolumn{2}{c}{ Sum } \\
& $\mathrm{n}$ & $\%$ & $\mathrm{n}$ & $\%$ & $\mathrm{n}$ & $\%$ \\
\hline Same ethnicity & 43 & 79.6 & 41 & 49.4 & 84 & 61.3 \\
Not same ethnicity & 11 & 20.4 & 42 & 50.6 & 53 & 38.7 \\
Sum & 54 & 100 & 83 & 100 & 137 & 100 \\
\hline
\end{tabular}

Table 5. Logistic regression on obtaining job information through informal channels (formal channels =baseline).

$\mathrm{n}=596$ 1 2 3 


\begin{tabular}{|c|c|c|c|c|c|c|}
\hline & $\begin{array}{l}\text { Odds } \\
\text { ratio }\end{array}$ & Sig. & $\begin{array}{l}\text { Odds } \\
\text { ratio }\end{array}$ & Sig. & $\begin{array}{l}\text { Odds } \\
\text { ratio }\end{array}$ & Sig. \\
\hline \multicolumn{7}{|l|}{ Ethnic background } \\
\hline Swedish & 1.00 & ref & 1.00 & ref & 1.00 & ref \\
\hline Assyrian/Syriac & 1.52 & 0.08 & 1.48 & 0.10 & 1.36 & 0.21 \\
\hline Kurdish & 0.91 & 0.80 & 0.83 & 0.63 & 0.80 & 0.56 \\
\hline Turkish & 1.79 & 0.01 & 1.57 & 0.05 & 1.63 & 0.04 \\
\hline Unknown/Other & 0.93 & 0.91 & 0.86 & 0.82 & 0.84 & 0.79 \\
\hline \multicolumn{7}{|l|}{ Education } \\
\hline Primary & & & 1.00 & ref & 1.00 & ref \\
\hline Secondary & & & 0.47 & 0.18 & 0.48 & 0.19 \\
\hline Tertiary & & & 0.26 & 0.01 & 0.28 & 0.02 \\
\hline \multicolumn{7}{|l|}{ Neighbourhood } \\
\hline Born in Turkey $<5 \%$ & & & & & 1.00 & ref \\
\hline Born in Turkey $5-10 \%$ & & & & & 1.62 & 0.04 \\
\hline Born in Turkey $>10 \%$ & & & & & 2.04 & 0.09 \\
\hline
\end{tabular}

Table 6. Multinomial model on obtaining the job through a strong or weak tie. Reference category $=$ formal channel.

\begin{tabular}{lcccc}
$\mathrm{n}=596$ & \multicolumn{2}{c}{ Strong tie } & \multicolumn{2}{c}{ Weak tie } \\
& $\begin{array}{c}\text { Odds } \\
\text { ratio }\end{array}$ & Sig. & $\begin{array}{c}\text { Oddio } \\
\text { ratio }\end{array}$ & Sig. \\
\hline Ethnic background & & & & \\
Swedish & 1.00 & ref & 1.00 & ref \\
Assyrian/Syriac & 1.32 & 0.34 & 1.71 & 0.04 \\
Kurdish & 0.69 & 0.47 & 1.12 & 0.77 \\
Turkish & 1.54 & 0.10 & 1.50 & 0.09 \\
Unknown & 0.59 & 0.55 & 0.84 & 0.81 \\
Education & & & & \\
Primary & 1.00 & ref & 1.00 & ref \\
Secondary & 0.29 & 0.04 & 0.43 & 0.15 \\
Tertiary & 0.15 & 0.00 & 0.27 & 0.03 \\
Neighbourhood & & & & \\
Born in Turkey<5\% & 1.00 & ref & 1.00 & ref \\
Born in Turkey 5-10\% & 1.72 & 0.04 & 1.34 & 0.23 \\
Born in Turkey >10\% & 1.65 & 0.27 & 1.59 & 0.25 \\
\hline
\end{tabular}

